\title{
Etiopathogenetic mechanisms of fibromyalgia syndrome
}

\author{
Meccanismi eziopatogenetici della sindrome fibromialgica
}

\begin{abstract}
S. Stisi ${ }^{1}$, M. Cazzola ${ }^{2}$, D. Buskila ${ }^{3}$, M. Spath ${ }^{4}$, M.A.Giamberardino ${ }^{5}$, P. Sarzi-Puttini ${ }^{6}$, G. Arioli ${ }^{7}$, A. Alciati ${ }^{8}$, G. Leardini', R. Gorla ${ }^{10}$, A. Marsico ${ }^{11}$, F. Ceccherelli ${ }^{12}$, L. Bazzichi ${ }^{13}$, R. Carignola ${ }^{14}$, R.H. Gracely ${ }^{15}$, F. Salaffi ${ }^{16}$, F. Marinangeli ${ }^{17}$, R. Torta ${ }^{18}$, M. Di Franco ${ }^{19}$, G. Biasi ${ }^{20}$, G. Cassisi ${ }^{21}$, R. Casale ${ }^{22}$, L. Altomonte ${ }^{23}$, F. Atzeni ${ }^{6}$ (Italian Fibromyalgia Network)

${ }^{I}$ Rheumatology Unit, “G.Rummo" Hospital, Benevento, Italy; ${ }^{2}$ Unit of Rehabilitative Medicine "Hospital of Circolo", Saronno (VA), Italy; ${ }^{3}$ Department of Medicine H, Soroka Medical Center and Faculty of Health Sciences, Ben Gurion University, Beer Sheva, Israel; ${ }^{4}$ Friedrich-Baur-Institute, University of Munich, Germany; ${ }^{5}$ Ce.S.I. "G. D'Annunzio" Foundation, Department of Medicine and Science of Aging, “G. D'Annunzio”, University of Chieti, Italy; ${ }^{6}$ Rheumatology Unit, L. Sacco University Hospital, Milano, Italy; ${ }^{7}$ Division of Rehabilitative Medicine and Rheumatology, General Hospital of Pieve di Coriano (Mantua), Italy; ${ }^{8}$ Department of Psychiatry, L. Sacco University Hospital, Milan, Italy; ${ }^{9}$ Rheumatology Unit, SS Giovanni e Paolo Hospital, Venice, Italy; ${ }^{10}$ Rheumatology and Clinical Immunology, Spedali Civili and University of Brescia, Italy; ${ }^{11}$ Rheumatology Unit, Hospital of Taranto, Taranto, Italy; ${ }^{12}$ IOV (Veneto Cancer Institute), IRCCS, Department of Pharmacology and Anesthesiology, University of Padua, Italy; ${ }^{13}$ Department of Internal Medicine, Division of Rheumatology, S. Chiara Hospital, University of Pisa, Italy; ${ }^{14}$ S.C.D.U. Internal Medicine I, Department of Clinical and Biological Science, University of Turin, Italy; ${ }^{15}$ Department of Medicine, University of Michigan Medical School, Ann Arbor, Michigan, USA; ${ }^{16}$ Department of Rheumatology, Polytechnic University of the Marche Region, Ancona, Italy; ${ }^{17}$ Department of Anesthesiology and Pain Medicine, L'Aquila University, L'Aquila, Italy; ${ }^{18}$ Department of Neuroscience, University of Torino,

A.S.O. San Giovanni Battista of Turin, Turin, Italy; ${ }^{19}$ Chair of Rheumatology, University la Sapienza Rome, Rome, Italy;

${ }^{20}$ Unit of Rheumatology, University of Siena, Siena, Italy; ${ }^{21}$ Rheumatology Branch, Specialist Outpatients' Department, Belluno, Italy;

${ }^{22}$ Department of Clinical Neurophysiology and Pain Rehabilitation Unit, Foundation Salvatore Maugeri, IRCCS, Scientific Institute of Montescano, Montescano (PV), Italy; ${ }^{23}$ UOC of Rheumatology Hospital S. Eugenio, Rome, Italy
\end{abstract}

$\overline{\text { Competing interests: none declared }}$

\section{RIASSUNTO}

La sindrome fibromialgica (FMS) è una comune condizione cronica di dolore diffuso con meccanismi causali largamente sconosciuti, ma la sua patogenesi appare associata ad una alterazione del sistema nocicettivo a livello del sistema nervoso centrale. La FMS è spesso scatenata da influenze ambientali negative, specialmente se presenti nell'infanzia. In un feto, questi triggers ambientali possono influenzare lo sviluppo del sistema nervosa autonomo (ASN) e dell'asse ipotalamo-ipofisi-surrene (HPA). Frequente è la comorbidità di condizioni psicologiche che comprendono la depressione, gli attacchi di panico, l'ansia e il disturbo post-traumatico da stress (PTSD). Recenti evidenze suggeriscono che fattori genetici possano giocare un ruolo nella patogenesi della FMS. La sensibilizzazione centrale è stata da tempo associata con il dolore fibromialgico. Questo fenomeno descrive l'aumentata eccitabilità dei neuroni delle corna dorsali, che porta alla trasmissione di alterate informazioni nocicettive al cervello. La comprensione delle vie patogenetiche della FMS è supportata dall'osservazione delle risposte dei pazienti alle terapie neurofisiologicamente mirate e dalla ricerca di base.

Reumatismo, 2008; 60: Supplemento 1: 25-35

\section{INTRODUCTION}

F ibromyalgia syndrome (FMS) is a common chronic condition of widespread pain with causal mechanisms that are largely unknown. It is characterized by moderate to severe musculoskel-

Corresponding author:

Piercarlo Sarzi-Puttini, MD

Director of Rheumatology Unit

L. Sacco University Hospital, Milan, Italy

E-mail: sarzi@tiscali.it etal pain and allodynia, but its pathogenesis appears confined to the nociceptive structures of the central nervous system.

From a pathogenetic point of view, indeed, no clear muscle pathology has been demonstrated in FMS $(1,2)$, while increasing evidence suggests a disturbance in pain perception that is genetically conditioned. In our review we will consider five "keypoints" that we think determine the origin and maintenance of the pain syndrome that we define as fibromyalgia: "triggers," "genetics," "central 
sensitization," "neuroendocrine abnormalities" and "nervous autonomic amplification." (Fig. 1).

\section{The "triggers"}

Fibromyalgia is often triggered by negative environmental influences, especially if they occur in childhood. In a fetus, these environmental triggers may influence the development of the autonomic nervous system (ANS) and the hypothalamic-pituitary-adrenal axis (HPA), which represent the key components of the neuroendocrine response to stressors. Their functional alteration constitutes the main factor that predisposes individuals to develop many stress-related diseases in adulthood, including FMS (3).

Low birth weight also correlates with hyperactivity of the HPA in males and sympathetic hypertone in females; therefore, it seems that these individuals have a more intense cardiovascular response to stressors (4). A history of childhood adversity, violence or stressors may cause a higher incidence of certain co-morbid conditions in adult patients with FMS such as major depression $(5,6)$.

Likely the reaction to the stress induced by these traumatic events, which occurs in a critical period for the development of specific synapses, induces alterations in the central nervous system (7).

Although a direct causal relationship between infectious diseases and FMS has not been demonstrated, it seems reasonable, however, that infections can, in some way, act as triggering agents. The onset of FMS, in fact, has been allied with multiple vaccinations for infectious diseases, viruses or bacteria (8). It is possible that the hypothetical infectious, natural or attenuated agent acts by indirectly stimulating production of cytokines that take part in the multiple physiological functions that are altered in patients with FMS.

Evidence supports a high prevalence of FMS among patients with numerous chronic infections, including Epstein Barr virus, herpes 6-virus, HIV and, recently, HTLV-I virus $(9,10)$.

Sleep disturbance could trigger mechanisms of FMS. Moldofsky (11), in fact, artificially reproduced fibromyalgia-like symptomatology in healthy volunteers by using an acoustic stimulus of an intensity that was insufficient to provoke awakening yet was able to disturb non-REM sleep. However, just as altering sleep physiology can induce the appearance of musculoskeletal pain, the inverse is also true: nociceptive muscular stimulation applied to healthy volunteers during sleep can alter EEG patterns (12).
The risk of developing FMS seems to be increased in patients with chronic painful conditions of another nature; more than $80 \%$ of patients, in fact, report that they have suffered from a chronic localized painful condition before the generalization of pain (13). In patients affected by symptomatic hip osteoarthritis abnormalities of the inhibitory system for nociception, similar to that documented in FMS patients, have been found; these abnormalities normalize following successful prosthetic treatment of the hip (14). Nociceptive persistent inputs are sufficiently intense; therefore, they could induce the generalization of pain and insurgence of FMS in predisposed subjects.

A particular sensitivity to multiple chemical substances would be the cause of multiple chemical sensitivity syndrome, a dysfunctional syndrome that is closely associated with FMS and chronic fatigue syndrome. Mercury, nickel, and silicone, which is commonly used in surgical breast implants, are substances that are frequently cited as possible causes of dysfunctional syndromes, such as FMS $(15,16)$.

Of particular importance as triggers of FMS are psychological conditions that can lead to catastrophizing of pain $(17,18)$ or life events and, therefore, cause additional stress. There is increasing evidence supporting the comorbidity of FMS and psychological conditions. These conditions include depression, panic disorders, anxiety, and post-traumatic stress disorder (PTSD). The nature of the relationship between depression and FMS is not fully understood. Depression is a common denominator among chronic painful conditions (15); it has been hypothesized that chronic pain causes depression, or vice versa, and that chronic pain syndromes are variants of depression. A link between PTSD symptoms and FMS has been reported, and both conditions share similar symptomatology and pathogenetic mechanisms (19).

The preexistence of chronic stressful conditions prior to the onset of FMS is frequently demonstrated. The symptomatology that is reported by fibromyalgia patients seems to be influenced negatively by chronic stressful situations, while positive correlations with acute stressful events have not been found (20). In addition, FMS patients show higher levels of stress compared to controls (21).

\section{Genetics}

Recent evidence suggests that genetic factors may play a role in the pathogenesis of FMS (22-24). Certain environmental factors ("stressors") may 
trigger the development of FMS in genetically predisposed individuals (25).

A number of studies published over recent years have documented increased incidence of FMS among family members of patients suffering from this syndrome (26-28).

Buskila et al. found that $28 \%$ of offspring of FMS patients fulfill the American College of Rheumatology (1990) classification criteria for the diagnosis of FMS (26). Buskila et al. reported another study, we reported that the prevalence of FMS among blood relatives of patients with FMS was $26 \%$, and that FMS prevalence in male and female relatives was $14 \%$ and $41 \%$, respectively (27). Arnold and colleagues (28) tested the hypotheses that FMS and measures of pain and tenderness aggregate in families and that FMS co-aggregates with major mood disorder. They performed a family interview study of 78 probands with FMS and 40 probands with rheumatoid arthritis (RA). They assessed FMS and major mood disorder in a total of 533 first degree relatives of FMS probands and a total of 272 first degree relatives of RA probands. FMS was found to aggregate strongly in families: the odds ratio measuring the odds of FMS in a relative of a proband with FMS versus the odds of FMS in relative of a proband with RA was 8.5. The clear familial aggregation in FMS and related conditions may represent either genetic or environmental influence, or most likely a combination of both.

Based on the strong evidence of a familial aggregation in FMS, a considerable amount of research has been conducted in search of the genetic underpinnings of this phenomenon. At present no evidence has emerged to suggest a monogenic mode of transmission, and a multifactorial mode of transmission is generally presumed.

Research done in recent years has demonstrated a role for polymorphisms of genes in the serotonergic, dopaminergic and catecholaminergic systems in the etiology of FMS.

Offenbaecher and colleagues (29) analyzed the genotypes of the promoter region of the serotonin transporter gene (5-HTT) in 62 patients with FMS and 110 healthy controls. A significantly higher frequency of the S/S genotype of the serotonin transporter promoter region was found in FMS patients $(31 \%)$ compared with healthy controls (16\%). The S/S subgroup exhibited higher mean levels of depression and psychological distress. It was suggested that the results support the notion of altered serotonin metabolism in at least a subgroup of patients with FMS.
In another study, these researches reported on a significantly different genotype distribution in FMS patients with a decrease in $\mathrm{T} / \mathrm{T}$ and an increase in both T/C and C/C genotypes compared to the control population (30).

Cohen and colleagues (31) performed genotyping in a group of 99 female FMS patients from two Israeli ethnic groups. Additionally, each patient was assessed with the Tridimensional Personality Questionnaire (TPQ). The results of this study confirm the association between FMS and the serotonin transporter promoter region (5 - HTTLPR) polymorphism in two ethnic groups in Israel, Jewish and Bedouins. A significant association between 5 - HTTLPR polymorphism and anxiety-related personality traits was found as well (31).

Zubieta and colleagues (32) examined the influence of a common functional genetic polymorphism affecting the metabolism of catecholamines on the modulation of responses to sustained pain in humans. Individuals homozygous for the Met 158 allele of the catechol - O methyltransferase (COMT) polymorphism (Val $158 \mathrm{Met}$ ) show diminished regional mu-opioid system responses to pain compared with heterozygotes. These effects were accompanied by higher sensory and affective ratings of pain and a more negative internal affective state.

It was concluded that the COMT Val 158 Met polymorphism influences the human experience of pain and may underlie interindividual differences in the adaptation and responses to pain and other stressful stimuli (32).

Gursory and colleagues (33) have reported on the involvement of COMT gene polymorphism in patients with FMS. Recently, Vargas-Alarcon et al. (35) reported that in a group of Spanish patients, there was an association between FMS and the COMT haplotype. However, this association was not observed in Mexican patients.

Buskila and colleagues (35) reported a significant decrease in the frequency of the 7 repeat allele in exon III of the DR receptor gene in FMS patients and also demonstrated an association between the polymorphism and the low novelty seeking personality trait. Altogether, recent evidence suggests a role for polymorphism of genes in the serotonergic, dopaminergic and catecholaminergic systems in the etiopathogenesis of FMS.

Thus recent evidence suggests a role for genetic and familial factors in the development of FMS. The mode of inheritance in FMS is unknown, but it is most probably polygenic. Recognition of these 


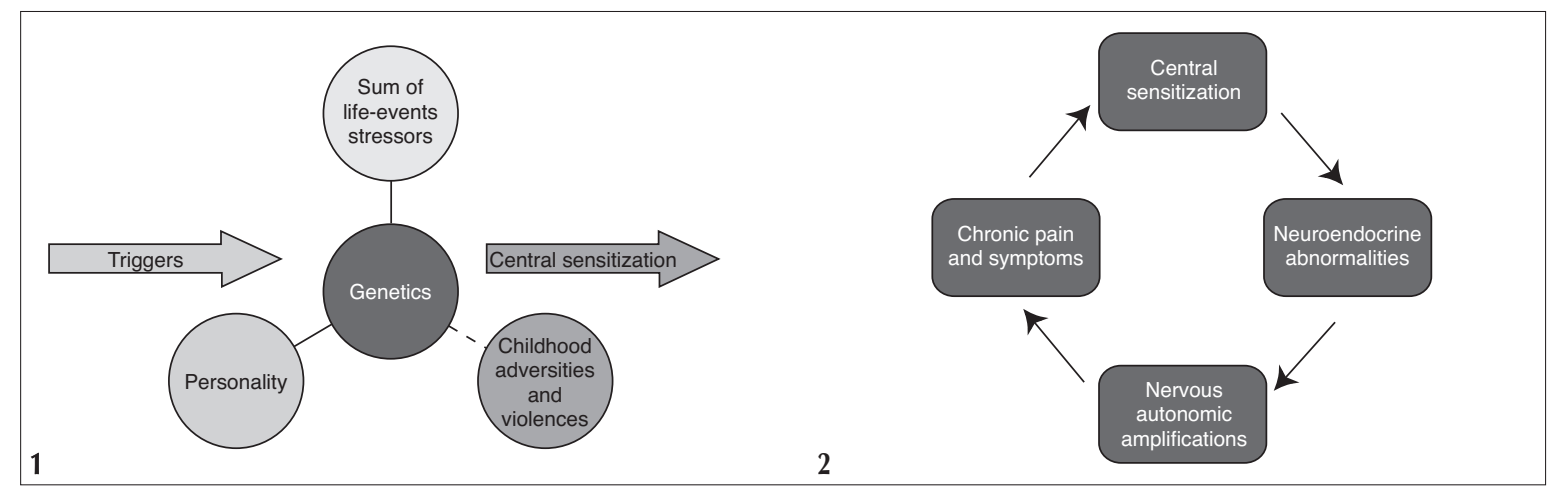

Figures 1 - Modified from Van Houdenhove (106) - and $\mathbf{2}$ synthesize our proposal for the pathogenesis of FMS. From exposed it's probable that triggers cause a central sensitization when they interact in genetically predisposed individuals. Then central sensitization creates a vicious circle by provoking neuroendocrine abnormalities and nervous autonomic amplifications, which subsequently cause a chronic maintenance painful syndrome.

gene polymorphisms may help to better subgroup FMS patients and to guide a more rational pharmacologic approach.

\section{Central sensitization}

Central sensitization has long been considered to be associated with FMS pain (36) (Fig. 1). It describes enhanced excitability of dorsal horn neurons, then transmission of altered nociceptive information to the brain. "Wind-up" (temporal summation) is the second mechanism increasing pain: a painful stimulus is applied steadily but the pain is perceived as increasing in intensity while applied subsequently $(37,38)$. Receptor fields increase as well, resulting in a larger distribution of the pain (39-41).

These phenomena of functional neuroplasticity are predominantly mediated by activation of $N$-methylD-aspartate (NMDA) receptors (42-44). Persistent activation of NMDA receptors may lead into structural alterations/reorganisation of the whole dorsal horn synapse. Again, the result may be chronic spinal amplification of the nociceptor input.

A descending pain inhibitory system originates in neurons of the periaqueductal gray matter, with descending projections to the nucleus raphe magnus and other nuclei in the rostral medulla. The neurons in these nuclei project via the dorsolateral funiculus to the spinal dorsal horn with projections in different nuclei of the rostral medulla, where they inhibit nociceptive neurons by releasing (among other neuropeptides) serotonin. But also noradrenergic neurons in the medulla are involved. NE and 5HT are key neurotransmitters in descending inhibitory pain pathways. Increasing the availability of NE and 5-HT may promote pain inhibition centrally (45-48).
As the system acts predominantly on the nociceptive input from deep tissues, an impairment of the descending inhibition will increase the ongoing activity and excitability particularly in dorsal horn neurons that process information from deep nociceptors. In patients, this may result in spontaneous pain and tenderness mainly in deep tissues. As the terminations of the descending neurons have a widespread distribution in the spinal cord, a dysfunction of the descending system may result in, or contribute to, the symptom of widespread pain observed in FMS (49).

A recent study by Harris et al. (50) compared a sample of 17 FMS patients and 17 age- and sex-matched healthy controls using mu-opioid receptor (MOR) positron emission tomography. It demonstrated that FMS patients display reduced MOR within several regions that play an important role in pain regulation, such as the nucleus accumbens, the dorsal cingulate, and the amygdala. These results indicate altered endogenous opioid analgesic activity in FMS and explain why exogenous opiates appear to have reduced efficacy in this population.

A previous study by the same group (51) suggested that pain catastrophizing is significantly associated with increased activity in some brain areas related to anticipation of pain (medial frontal cortex, cerebellum), attention to pain (dorsal ACC, dorsolateral prefrontal cortex), and emotional aspects of pain (claustrum, closely connected to amygdala). These results suggest that catastrophizing influences pain perception by altering attention and anticipation, and heightening emotional responses to pain.

Also some neurotransmitters play an important role in the central sensitization of the widespread pain that characterizes FMS. Serotonin is crucial in me- 
diating pain pathways; it was the first neuropeptide to be studied extensively in FMS and hypothesized to be involved in abnormal pain processing (52, 53). The co-morbidity of psychiatric conditions, such as depression, and the alterations of sleepwake cycles, mediated by $5-\mathrm{HT}$, seemed to support 5-HT dysregulation (54).

Levels of 5-HT, its precursor tryptophan, and its metabolites 5-HIAA and 5-HTP were measured in the blood, in the cerebrospinal fluid (CSF), and in the urine of FMS patients. The most consistent results of all attempts to confirm an abnormality in 5-HT neurotransmission were derived from CSF samples. The pioneering studies did not measure 5HT directly but found decreased levels of 5-HIAA in FMS patients as compared to controls, including both pain-free and low back pain subjects (5557). The results from studies measuring 5-HT levels in the serum of patients with FMS were less consistent. One group documented higher 5-HT levels in FMS patients versus controls (58), even using platelet-rich plasma for the assay, whereas another group found lower serum 5-HT levels in FMS than in RA patients (54). The hypothesis was that increased platelet activation may lead to a release of 5-HT into the plasma fraction. FMS patients with a high plasma-to-serum 5-HT ratio presented with a higher frequency of orofacial pain and anxiety (59). Similarly in another study, the number of tender points and serum 5-HT levels significantly correlated inversely, comparing FMS patients with both RA patients and healthy controls (52). Whether or not the inconsistency may be explained by changes within the serotonin transporter has been discussed. A polymorphism in the 5-HT transporter gene regulatory region (S/S genotype) is associated with decreased 5-HT transporter messenger RNA transcription and decreased 5-HT uptake in vitro. As mentioned previously, this polymorphism has been shown to have a significantly higher distribution in FMS cohort (29).

To summarize, a dysregulation of 5-HT metabolism in FMS is likely but has not been proven to be the sole cause of central sensitization of FMS.

Substance P, an 11-amino-acid neuropeptide, acts as a neuromodulator via the NK1 receptor. It sensitizes the neurons to the effects of other neuromodulators. Stimulating the release of 5-HT in the spinal cord decreases the release of substance $\mathrm{P}$ into the spinal cord (60).

Substance P levels in the CSF of FMS patients have been found to be reproducibly high in five different studies (61-64). A trend toward correlation of
CSF substance $\mathrm{P}$ levels and pain severity in FMS over time has been suggested (65). Other chronic pain states, such as low back pain and painful neuropathy, present with low levels of CSF substance P (66-69). High CSF concentration of substance P represents the most prominent neurochemical abnormality found in FMS patients.

There are significant negative correlations between levels of substance $\mathrm{P}$ and 5-HT, its precursor tryptophan (TRP), and its primary metabolite 5-HIAA in the serum of patients with FMS. High serum concentrations of 5-HIAA and TRP showed a significant relation to low pain scores. Low levels of 5-HIAA and high concentrations of substance P were both positively correlated with more severe sleep disturbance (70). Nerve growth factor (NGF), which stimulates the production of substance $\mathrm{P}$ in small, afferent, unmyelinated neurons, was found to be elevated in the CSF of FMS patients with primary FMS, but not in FMS with an associated painful inflammatory condition (secondary FMS) (71). This finding addresses the clinical finding of subgroups in FMS (72-74). Elevated CSF substance $\mathrm{P}$ could be a common link between primary and secondary FMS, but the groups differ with regard to the mechanism responsible for the elevated substance P. In primary FMS, NGF seems to induce the elevated CSF substance P from central interneurons. In secondary FMS, the peripheral inflammation, so characteristic of the underlying rheumatic or infectious conditions, may be responsible for the elevated CSF substance P. For these reasons, NGF could be critical to the initiation or perpetuation of the painful symptoms of primary but not secondary FMS (71).

\section{Neuroendocrine abnormalities}

The neuroendocrine system, together with the autonomic nervous system and immune system, plays a fundamental role in the maintenance of the homeostasis of the organism in a large variety of environmental situations, namely stressful events of both physical and psychological origin. FMS is frequently associated with a rich history of stressful/traumatic events (75) and is characterized by a number of symptoms similar to those typical of stress-related conditions, such as irritable bowel syndrome or chronic fatigue syndrome.

\section{The hypothalamic-pituitary-adrenal axis (HPA-axis)}

FMS patients have been shown to present with HPA axis alterations (76-80). Compared to con- 
trols, they present low 24-h serum cortisol levels; abnormal circadian pattern of cortisol concentration and blunted serum cortisol responses to corticotropin-releasing hormone $(\mathrm{CRH})$, i.e., when $\mathrm{CRH}$ is released by the hypothalamus, there is a disproportionately high release of corticotrophin by the pituitary gland and disproportionately small release of cortisol by the adrenal gland. This latter result suggests an abnormal response of FMS patients to stress, and thus, an inadequate reaction to a number of stressful events, such as trauma or infection (81). Interestingly, when synthetic CRH is injected in FMS patients this abnormal response is not present, and the patients behave like normal control subjects. This suggests that there might be a different sensitivity of adrenal tissue to endogenous and exogenous CRH in FMS. On the whole, however, there is no evidence to support any structural abnormality in the endocrine organs which comprise the HPA axis; thus, it seems that the changes found in hormone production under activation of the axis are functional in patients with FMS (82).

Dysregulation of the HPA axis can potentially account for several symptoms in FMS, including fatigue, primarily, as well as depression and sleep disturbance; these symptoms are often present in subjects with a reduced activity of the axis (as in withdrawal from glucocorticoid therapy, or in Addison's disease) or in individuals with genetically altered HPA axis function (83). A link with pain is also present. For instance, a recent study by McLean et al. (84) showed a significant association between levels of CRH in CSF and pain levels in patients with FMS.

Increased central levels of CRH also produce analgesia in animals (85). Activation of the HPA axis stimulates the release of the opioid beta-endorphin, corticotrophin, and cortisol, which, thanks to its anti-inflammatory properties, has the potential of reducing pain (83), though it should be underlined that in FMS, specifically, corticosteroids are not effective (86).

\section{The hypothalamic-pituitary-thyroid axis (HPT-axis)}

The hypothalamic-pituitary-thyroid axis function would seem altered in FMS patients as the release of thyrotropin-releasing hormone stimulates less thyrotropin, triiodothyronine and thyroxin production than normal. This is possibly the result of some pituitary dysfunction secondary to the documented impaired stress response in FMS (87).

\section{The hypothalamic-pituitary-gonadal axis (HPG-axis)}

Though not many studies have been performed in this area, the results of those available so far provide no evidence for any abnormality in gonadotropin secretion or gonadal steroid levels in FMS $(88,89)$. Thus a deficit of sex hormones does not appear to be part of the manifestations of FMS.

\section{Growth hormone (GH)}

A number of research studies have been devoted to evaluation of circulating levels of growth hormone in FMS. These levels tend to be normal during waking hours and are slightly reduced during sleep. It is well known that stage 4 of sleep is disrupted in FMS, and this is the phase when GH is secreted; it remains to be established if the decreased $\mathrm{GH}$ is the consequence of disrupted sleep or of a decreased GH-stimulation by sleep. FMS patients have increased levels of corticotrophin, and corticotrophin increases hypothalamic somatostatin secretion. Since somatostatin is one of the hormones that inhibits GH via the hypothalamic-pituitary portal system this may also contribute to their relative GH insufficiency. Supplementation with GH has provided relatively positive results, at least in a subpopulation of FMS patients; however, the high costs of the hormone, combined with the unpleasantness of the modality of administration do not encourage the use of this therapy on a large scale (90).

FMS patients have been shown to present with many neurochemical alterations, e.g., norepinephrine deficit, lower concentrations of beta-endorphin in peripheral blood mononuclear cells (91), low serum serotonin levels and low level of the serotonin metabolite (5-HIAA) (92) in the CSF, increased levels of substance $P$ and nerve growth factor (NGF) - a promoter of substance $\mathrm{P}$ synthesis in CSF $(93,94)$, abnormal dopaminergic transmission. Regarding the latter, a recent review by Wood (95) focused on the mesolimbic dopaminergic system as a possible contributor to central pain states; in animals acute stress activates mesolimbic dopamine neurons inducing analgesia; however, prolonged stress decreases mesolimbic dopaminergic output and creates a hyperalgesic state. A recent study by Malt et al (96) compared the response of female patients with FMS and healthy controls to buspirone, showing an increased prolactin response in the FMS group, a result that was attributed by the researchers to altered dopamine sensitivity in FMS. 
Collectively, these neurotransmitter abnormalities may play a role in HPA function and control in FMS (97).

To date, however, the means by which HPA axis dysfunction develops in FMS still remains unclear.

\section{Autonomic nervous system (ANS) amplification}

The ANS is the principal regulatory system of the body; it maintains essential involuntary functions, e.g., the vital signs (blood pressure, pulse, respiration, and temperature) and balances the function of all internal organs. It is a complex network activated by nerve centers located in the spinal cord, brain stem, hypothalamus and thalamus; centers that also receive input from the limbic area and other higher brain regions.

Emotions such as fear or anger, therefore, produce immediate biological responses, such as pupil dilatation or tachycardia. Through their neurotransmitters (catecholamines for the sympathetic system), the two divisions of the peripheral autonomic system, sympathetic and parasympathetic, have antagonistic actions on most functions of the body, but their proper balance is essential to preserve homeostasis (98).

A number of studies have demonstrated alterations of the ANS in FMS, the most recent ones using methodologies such as power spectrum analysis of heart rate variability (HRV) and tilt table test.

Vaeroy, et al. (99) demonstrated a decreased sympathetic response to painful and auditory stimuli. Studies with power spectrum analysis of HRV showed decreased 24-h HRV with persistent nocturnal sympathetic hyperactivity associated with increased number of awakenings, decreased sympathetic response to several stressors and abnormal sympathovagal responses during postural changes. The HRV studies reflect a basal autonomic state of hyperactivation characterized by increased sympathetic and decreased parasympathetic tone (i.e., a sympathetic basal hyperactivity with hyporeactivity) (100, 101). Abnormal HRV in FMS, consistent with excessive sympathetic activity, especially in women, has been reported by several investigators (99). In a recent study, Furlan, et al. (102) investigated whether FMS is characterized by alterations in the cardiovascular autonomic response to gravitational stimulus (using the stepwise tilting); they found a reduced ability to enhance the sympathetic activity to the vessels and withdraw the vagal modulation to the sino-atrial node.

The dysautonomia in FMS would thus be charac- terized as a sympathetic nervous system that is persistently hyperactive but is hyporeactive to stress. This apparent paradox (sympathetic hyperactivity with hyporeactivity) nevertheless agrees with the basic physiological principle showing that chronic hyperstimulation of the beta-adrenergic receptors leads to receptor desensitization and down-regulation (99). It has been suggested that the dysautonomia in FMS could be at least in part responsible for the pain of the syndrome - similarly to what happens in classic sympathetic-maintained pain conditions.

ANS dysfunction may also explain a number of the other clinical symptoms of FMS. Due to a ceiling effect, the hyperactive sympathetic nervous system in FMS would become unable to further respond to different stressors, thus explaining the constant fatigue and morning stiffness. Relentless sympathetic hyperactivity may explain sleep disorders, anxiety, pseudo-Raynaud's phenomenon, sicca symptoms, and intestinal irritability.

Further studies support the altered sympathetic function in FMS. Anderberg, et al. (103) found high serum levels of neuropeptide Y (NPY) in FMS vs healthy controls, which was interpreted as a sign of increased sympathetic activity (prolonged and/or repeated stress) since NPY is co-released with noradrenaline from sympathetic neurons. Wallace, et al. (104) showed high serum concentrations of IL8 in FMS vs healthy controls, another interesting finding since IL-8 has been associated with sympathetically dependent hyperalgesia. Along the same line, Martinez-Lavin (98) showed that a subcutaneous injection of noradrenaline induced pain more frequently and with a higher intensity in FMS patients vs RA patients or vs healthy controls.

The HPA axis and the ANS have multiple sites of interaction. At present it is not clear if decreased ANS activity and altered neuroendocrine function may contribute to the pain and related symptoms of the syndrome or if they are the consequence of pain.

It is frequent for FMS patients to present a history of emotional or physical trauma before the onset of FMS symptoms (105). Stress is known to reduce the neuroendocrine and ANS stress response; therefore, stressful events may represent the triggering factor for the neuroendocrine and ANS abnormality in FMS. However, it is also possible that the symptoms of FMS (pain, sleep disturbance, fatigue, etc.), experienced on a chronic basis, may affect the function of the HPA axis and ASN. As a matter of fact, a number of studies have shown that a reduction of 
stress, obtained, for instance, through relaxation training or exercise training, produces a decrease in the sympathetic activity (as evaluated via spectral analysis, resting heart rate, circulating levels of catecholamines).

Pain may also explain the reduced neuroendocrine and ANS responsiveness since there is a high level of substance $\mathrm{P}$ in the CSF in FMS, and substance $\mathrm{P}$ is a potent inhibitor of $\mathrm{CRH}$.

\section{CONCLUSIONS}

Understanding of pathogenetic pathways in FMS has advanced from observing patient responses to neurophysiologically targeted therapies and basic research. The model of central sensitization represents the most common and most accepted hypotheses about the underlying mechanisms in the pathogenesis of FMS.

\section{SUMMARY}

Fibromyalgia syndrome (FMS) is a common chronic condition of widespread pain with causal mechanisms that are largely unknown. It is characterized by moderate to severe musculoskeletal pain and allodynia, but its pathogenesis appears confined to the nociceptive structures of the central nervous system. FMS is often triggered by negative environmental influences, especially if they occur in childhood. In a fetus, these environmental triggers may influence the development of the autonomic nervous system (ANS) and the hypothalamic-pituitary-adrenal axis (HPA). Increasing evidence supports the comorbidity of psychological conditions including depression, panic disorders, anxiety, and post-traumatic stress disorder (PTSD). Recent evidence suggests that genetic factors may play a role in the pathogenesis of FMS. Central sensitization has long been associated with FMS pain. It describes enhanced excitability of dorsal horn neurons, which leads to transmission of altered nociceptive information to the brain. Understanding of pathogenetic pathways in FMS has advanced beyond observing patient responses to neurophysiologically targeted therapies and basic research.

Key words - Central sensitization, neuroendocrine abnormalities, genetic factors, autonomic nervous system.

Parole chiave - Sensibilizzazione centrale, alterazioni neuroendocrine, fattori genetici, alterazioni del sistema nervoso.

\section{REFERENCES}

1. Sarnoch H, Adler F, Scholz OB. Relevance of muscular sensitivity, muscular activity, and cognitive variables for pain reduction associated with EMG feedback in fibromyalgia. Percept Mot Skills 1997; 84: 1043-50.

2. Jacobsen S, Petersen IS, Danneskiold-Samsoe B. Clinical features in patients with chronic muscle pain with special reference to fibromyalgia. Scand J Rheumatol 1993; 22: 69-76.

3. Kajantie E. Fetal origins of stress-related adult disease. Ann NY Acad Sci 2006; 1083: 11-27.

4. Phillips DI and Jones A. Fetal programming of autonomic and HPA function: do people who were small babies have enhanced stress response? J Phisiol 2006; 572: 45-50.

5. McBeth J, Morris S, Benjamin S, Silman AJ, Macfarlane GJ. Associations between adverse events in childhood and chronic widespread pain in adulthood: are they explained by differential recall? J Rheumatol 2001; 28: 2305-9.

6. Imbierowicz K, Egle UT. Childhood adversities in patients with fibromyalgia and somatoform pain disorder. Eur J Pain 2003; 7: 113-9.

7. Crofford LJ. Violence, stress, and somatic syndromes. Trauma Violence Abuse 2007; 8: 299-313.

8. Ablin JN, Shoenfeld Y, Buskila D. Fibromyalgia, in- fection and vaccination: two more parts in the etiological puzzle. J Autoimmun 2006; 27: 145-52.

9. Goldenberg DL: Do infections trigger fibromyalgia? (editorial). Arthritis Rheum 1993; 36: 1489-92.

10. Cruz BA, Catalan-Soares B, Proietti F. Higher prevalence of fibromyalgia in patients infected with human T cell lymphotropic virus type I. J Rheumatol 2006; 33: 2300-3.

11. Moldofsky H, Scarisbrick P, England R, Smythe H. Musculoskeletal symptoms and non-REM sleep disturbance in patients with "fibrositis syndrome" and healthy subjects. Psychosom Med 1975; 47: 341-51.

12. Lavigne G, Brousseau M, Kato T Mayer P, Manzini C, Guitard F, et al. Experimental pain perception remains equally active over all sleep stages. Pain 2004; 110: 646-55.

13. Burckhardt CS, Clark SR, Campbell SM, O'Reilly $\mathrm{CA}$ and Bennett RM. Events and comorbidities associated with the onset of fibromyalgia. J Musculoskel Pain 1995; 3: 71.

14. Kosek E and Ordeberg G. Abnormalities of somatosensory perception in patients with painful osteoarthritis normalize following successful treatment. Eur J Pain 2000; 4: 229-38.

15. McBeth J and Silman AJ. The role of psychiatric disorders in fibromyalgia. Curr Rheumatol Reports 2001; 3: 157-64.

16. Bell IR, Baldwin CM, Schwartz GE. Illness from low 
levels of environmental chemicals: relevance to chronic fatigue syndrome and fibromyalgia. Am J Med 1998; 105: 74S-82S.

17. Vasey FB, Zarabadi SA, Seleznick M, Ricca L. Where there's smoke there's fire: the silicone breast implant controversy continues to flicker: a new disease that needs to be defined. J Rheumatol 2003; 2092-4.

18. Gracely RH, Geisser ME, Giesecke T, Grant MA, Petzke F, Williams DA, Clauw DJ. Pain catastrophizing and neural responses to pain among persons with fibromyalgia. Brain 2004; 127: 835-43.

19. Buskila D, Cohen H. Comorbidity of fibromyalgia and psychiatric disorders. Curr Pain Headache Rep 2007; 11: 333-8.

20. Hazlett DJ, Haines SN. Fibromyalgia: a time series analysis of the stressor-physical symptom association. J Behav Med 1992; 15: 541-8.

21. Kosek E, Fibromyalgia. In: F Cervero and TS Jensen (Eds), Handbook of Clinical Neurology, Vol 81 ( $3^{\text {rd }}$ series), Elsevier, Edinburgh, London, New York, Oxford, Philadelphia, St Louis, Sydney, Toronto, 2006; 763-77.

22. Buskila D, Neumann L. Genetics of fibromyalgia. Curr Pain Headache Rep 2005; 9: 313-5.

23. Buskila D, Neumann L, Press J. Genetic factors in neuromuscular pain. CNS Spectr 2005; 10: 281-4.

24. Buskila D, Sarzi Puttini P. Genetic aspects of fibromyalgia syndrome. Arthr Res Ther 2006; 8: 21825.

25. Clauw DJ, Crofford LJ. Chronic widewspread pain and fibromyalgia, what we know and what we need to know. Best Pract Res Clin Rheumatol 2003; 17 : 685-701.

26. Buskila D, Neumann L, Hazanov I, Carmi R. Familial aggregation in the fibromyalgia syndrome. Semin Arthritis Rheum 1996; 26: 605-11.

27. Buskila D, Neumann L. Fibromyalgia Syndrome (FM) and nonarticular tenderness in relatives of patients with FM. J Rheumatol 1997; 24: 941-4.

28. Arnold LM, Hudson J, Hess EV, Ware AE, Fritz DA, Auchenbach MB, et al. Family study of fibromyalgia. Arthritis Rheum 2004; 50: 944-52.

29. Offenbaecher M, Bondy B, de Jong S, Glalzender K, Kruger M, Schoeps P, Ackenheil M. Possible association of fibromyalgia with a polymorphism in the regulatory region. Arthritis Rheum 1999; 42: 2482-8.

30. Bondy B, Spaeth M, Offenbaecher M, Glatzeder K, Stratz T, Schwarz M, et al. The T 102 C polymorphism of the 5-HT2A receptor gene in fibromyalgia. Neurobiol Dis 1999; 6: 433-39.

31. Cohen H, Buskila D, Neumann L, Ebstein RP. Confirmation of an association between fibromyalgia and serotonin transporter promoter region (5-HTTLPR) polymorphism and relationship to anxiety related personality traits. Arthritis Rheum 2002; 46: 845-7.

32. Zubieta JK, Heitzeg M, Smith YR. COMT Val 158 Met genotype affects mu-opioid neurotransmitter responses to a pain stressor. Science 299; 5610: 1240-3.

33. Gursoy S, Erdal E, Herken H, Ma denci E, Ala B, Erdal N. Significance of catechol - O - methyl - trans- ferase gene polymorphism in fibromyalgia syndrome. Rheumatol Int 2003; 23: 104-7.

34. Vargas - Alarcon G, Fragosos JM, Gruz - Robeles D, Vergas A, Lao - Villadoniga JI, Garcia - Fructuoso F. Catechol - O - methyltransferase gene haplotypes in Mexican and Spanish patients with fibromyalgia. Arthritis Res Ther 2007; 9: R 110.

35. Buskila D, Cohen H, Neumann L, Ebstein RP. An association between fibromyalgia and the dopamine D4 receptor exon III repeat polymorphism and relationship to personality traits. Mol Psychiatry 2004; 9: 7301.

36. Yunus MB. Towards a model of pathophysiology of fibromyalgia: aberrant central pain mechanisms with peripheral modulation. J Rheumatol 1992; 19: 846-50.

37. Staud R, Vierck CJ, Cannon RL, Mauderli AP, Price DD. Abnormal sensitization and temporal summation of second pain (wind-up) in patients with fibromyalgia syndrome. Pain 2001; 91: 165-75.

38. Li J, Simone DA, Larson AA. Windup leads to characteristics of central sensitization. Pain 1999; 79: 7582.

39. Schadrack J, Zieglgänsberger W. Activity-dependent changes in the pain matrix. Scand J Rheumatol 2000; 113: 19-23.

40. Sorensen J, Graven-Nielsen T, Henriksson KG, Bengtsson M, Arendt-Nielsen L. Hyperexcitability in fibromyalgia. J Rheumatol 1998; 25: 152-5.

41. Zieglgansberger W, Herz A. Changes of cutaneous receptive fields of spino-cervical-tract neurones and other dorsal horn neurones by microelectrophoretically administered amino acids. Experimental Brain Research 1971; 13: 111-26.

42. Davies SN, Lodge D. Evidence for involvement of Nmethylaspartate receptors in 'wind-up' of class 2 neurones in the dorsal horn of the rat. Brain Res 1987; 424: 402-6.

43. Dickenson AH. Spinal cord pharmacology of pain. Br J Anaesth 1995; 75: 193-200.

44. Dickenson AH, Sullivan AF. Evidence for a role of the NMDA receptor in the frequency dependent potentiation of deep rat dorsal horn nociceptive neurones following $\mathrm{C}$ fibre stimulation. Neuropharmacology 1987; 26: 1235-8.

45. Staud R, Domingo M. Evidence for abnormal pain processing in fibromyalgia syndrome. Pain Med 2001; 2: 208-15.

46. Gebhart GF. Descending modulation of pain. Neurosci Biobehav Rev 2004; 27: 729-37.

47. Kosek E, Hansson P. Modulatory influence on somatosensory perception from vibration and heterotopic noxious conditioning stimulation (HNCS) in fibromyalgia patients and healthy subjects. Pain 1997; 70: 41-51.

48. Kranzler JD, Gendreau JF, Rao SG. The psychopharmacology of fibromyalgia: a drug development perspective. Psychopharmacol Bull 2002; 36: 165-213.

49. Mense S. Neurobiological concepts of fibromyalgia the possible role of descending spinal tracts. Scand J Rheumatol 2000; 29: 24-9. 
50. Harris RE, Clauw DJ, Scott DJ, McLean SA, Gracely RH, Zubieta JK. Decreased central mu-opioid receptor availability in fibromyalgia. J Neurosci 2007; 27: 10000-6.

51. Gracely RH, Geisser ME, Giesecke T, Grant MA, Petzke F, Williams DA, Clauw DJ. Pain catastrophizing and neural responses to pain among persons with fibromyalgia. Brain 2004; 127: 835-43.

52. Hrycaj P, Stratz T, Muller W. Platelet $3 \mathrm{H}$-imipramine uptake receptor density and serum serotonin levels in patients with fibromyalgia/fibrositis syndrome. J Rheumatol 1993; 20: 1986-8.

53. Yunus MB, Dailey JW, Aldag JC, Masi AT, Jobe PC. Plasma tryptophan and other amino acids in primary fibromyalgia: a controlled study. J Rheumatol 1992; 19: 90-4.

54. Moldofsky H. Sleep and musculoskeletal pain. Am J Med 1986; 81: 85-9.

55. Russell IJ. Neurochemical pathogenesis of fibromyalgia. Z Rheumatol 1998; 57: 63-6.

56. Russell IJ, Michalek JE, Vipraio GA, Fletcher EM, Wall K. Serum amino acids in fibrositis/fibromyalgia syndrome. J Rheumatol 1989; 19: 158-63.

57. Russell IJ, Vaeroy H, Javors M, Nyberg F. Cerebrospinal fluid biogenic amine metabolites in fibromyalgia/fibrositis syndrome and rheumatoid arthritis. Arthritis Rheum 1992; 35: 550-6.

58. Legangneux E, Mora JJ, Spreux-Varoquaux O, Thorin I, Herrou M, Alvado G, et al. Cerebrospinal fluid biogenic amine metabolites, plasma-rich platelet serotonin and $[3 \mathrm{H}]$ imipramine reuptake in the primary fibromyalgia syndrome. Rheumatology (Oxford) 2001; 40: 290-6.

59. Ernberg M, Voog U, Alstergren P, Lundeberg T, Kopp S. Plasma and serum serotonin levels and their relationship to orofacial pain and anxiety in fibromyalgia. J Orofac Pain 2000; 14: 37-46.

60. Murphy RM, Zemlan FP. Differential effects of substance $\mathrm{P}$ on serotonin-modulated spinal nociceptive reflexes. Psychopharmacology (Berl) 1987; 93: 118-21.

61. Bradley LA, Alberts KR, Alarcon GS. Abnormal brain regional cerebral blood flow $(\mathrm{rCBF})$ and cerebrospinal fluid (CSF) levels of substance $\mathrm{P}(\mathrm{SP})$ in patients and non-patients with fibromyalgia (FM). Arthritis Rheum [abstract] 1996; 39: 212.

62. Russell IJ, Orr MD, Littman B, Vipraio GA, A1boukrek D, Michalek JE, et al. Elevated cerebrospinal fluid levels of substance $\mathrm{P}$ in patients with the fibromyalgia syndrome. Arthritis Rheum 1994; 37 : 1593-601.

63. Vaeroy H, Helle R, Forre O, Kass E, Terenius L. Elevated CSF levels of substance $\mathrm{P}$ and high incidence of Raynaud phenomenon in patients with fibromyalgia: new features for diagnosis. Pain 1988; 32: 21-6.

64. Welin M, Bragee B, Nyberg F, Kristiansson M. Elevated substance $\mathrm{P}$ levels are contrasted by a decrease inmetenkephalin-ARG-PHE levels in CSF from fibromyalgia patients. J Musculoske Pain 1995; 3: 4.

65. Russell IJ. Advances in fibromyalgia: possible role for central neurochemicals. Am J Med Sci 1998; 315: 377-84.

66. Almay BG, Johansson F, Von Knorring L, Le Greves $\mathrm{P}$, Terenius L. Substance $\mathrm{P}$ in CSF of patients with chronic pain syndromes. Pain 1988; 33: 3-9.

67. Fischer HP, Eich W, Russell IJ. A possible role for saliva as a diagnostic fluid in patients with chronic pain. Semin Arthritis Rheum 1998; 27: 348-59.

68. Sjostrom S, Tamsen A, Hartvig P, Folkesson R, Terenius L. Cerebrospinal fluid concentrations of substance $\mathrm{P}$ and (met)enkephalin-Arg6-Phe7 during surgery and patient-controlled analgesia. Anesth Analg 1988; 67: 976-81.

69. Tsigos C, Diemel LT, White A, Tomlinson DR, Young RJ. Cerebrospinal fluid levels of substance P and calcitonin-gene-related peptide: correlation with sural nerve levels and neuropathic signs in sensory diabetic polyneuropathy. Clin Sci (Lond) 1993; 84: 305 11.

70. Schwarz MJ, Späth M, Müller-Bardorff H, Pongratz DE, Bondy B, Ackenheil M. Relationship of substance P, 5-hydroxyindole acetic acid and tryptophan in serum of fibromyalgia patients. Neuroscience Letters 1999; 259: 196-8.

71. Giovengo SL, Russell IJ, Larson AA. Increased concentrations of nerve growth factor in cerebrospinal fluid of patients with fibromyalgia. J Rheumatol 1999; 26: 1564-9.

72. Giesecke T, Williams DA, Harris RE, Cupps TR, Tian X, Tian TX, et al. Subgrouping of fibromyalgia patients on the basis of pressure-pain thresholds and psychological factors. Arthritis Rheum 2003; 48: 2916-22.

73. Muller W, Schneider EM, Stratz T. The classification of fibromyalgia syndrome. Rheumatol Int 2007; 27: 1005-10.

74. Turk DC, Okifuji A, Sinclair JD, Starz TW. Pain, disability, and physical functioning in subgroups of patients with fibromyalgia. J Rheumatol 1996; 23: 125562.

75. Stisi S, Venditti C, Sarracco I, Prevalenza di stressors percepiti in pazienti con fibromialgia primaria. Progressi in Reumatologia Clinica 2007; 1 (Suppl. 1): 67.

76. Dessein PH, Shipton EA, Stanwix AE, Joffe BI. Neuroendocrine deficiency-mediated development and persistence of pain in fibromyalgia: a promising paradigm. Pain 2000; 86:213-5.

77. Martinez-Lavin M. Biology and therapy of fibromyalgia. Stress, the stress response system and fibromyalgia, Arthritis Res Ther 2007; 9: 216-25.

78. Riedel W, Schlapp U, Leck S, Netter P, Neeck G. Blunted ACTH and cortisol responses to systemic injection of corticotropine-releasing hormone $(\mathrm{CRH})$ in fibromyalgia. Ann NY Acad Sci 2002; 966: 483-90.

79. Tsigos C, Chrousos GP. Hypothalamic-pituitaryadrenal axis, neuroendocrine factors and stress. J Psychosom Res 2002; 53: 865-71.

80. Wingenfeld K, Wagner D, Schmidt I, Meinlschmidt G, Hellhammer DH, Hein C. The low-dose dexam- 
ethasone suppression test in fibromyalgia. J Psychosom Res 2007; 62: 85-91.

81. Crofford LJ. Neuroendocrine abnormalities in fibromyalgia and related disorders. Am J Med Sci 1998; 315: 359-66.

82. Tanriverdi F, Karaca Z, Unluhizarci K, Kelestimur F. The hypothalamo-pituitary-adrenal axis in chronic fatigue syndrome and fibromyalgia syndrome. Stress 2007; 10: 13-25.

83. Sarzi-Puttini P, Atzeni F, Diana A, Doria A, Furlan R. Increased Neural sympathetic activation in fibromyalgia syndrome. Ann NY Acad Sci 2006; 1069: 109-17.

84. McLean SA, Williams DA, Stein PK, Harris RE, Lyden AK, Whalen G, et al. Cerebrospinal fluid corticotropin-releasing factor concentration is associated with pain but not fatigue symptoms in patients with fibromyalgia. Neuropsychopharmacology 2006; 31 : 2776-82.

85. Lariviere WR, Melzack R. The role of corticotrophinreleasing factor in pain and analgesia. Pain 2000; 84: $1-14$.

86. Abeles AM, Pillinger MH, Solitar BM, Abeles M. Narrative Review: The Pathophysiology of Fibromyalgia. Ann Int Med 2007; 146: 726-34.

87. Neeck G. Thyroid function in patients with fibromyalgia syndrome. J Rheumatol 1992; 19: 11202.

88. Korszun A, Young EA, Engleberg NC, Masterson L, Dawson EC, Spindler K, et al. Follicular phase hypothalamic pituitary-gonadal axis function in women with fibromyalgia and chronic fatigue syndrome. J Rheumatol 2000; 27: 1526-30.

89. Samborski W, Sobieska M, Pieta P, Drews K, Brzosko M. Normal profile of sex hormones in women with primary fibromyalgia. Ann Acad Med Stetin 2005; 51: 23-6.

90. Jones KD, Deodhar P, Lorentzen A, Bennett RM, Deodhar AA. Growth hormone perturbations in fibromyalgia: a review. Semin Arthritis Rheum 2007; 36: 357-79.

91. Panerai A, Vecchiet J, Panzeri P, Meroni PL, Scarone S, Pizzigallo E, et al. Peripheral Blood Mononuclear Cell [beta]-Endorphin Concentration Is Decreased in Chronic Fatigue Syndrome and Fibromyalgia but Not in Depression: Preliminary report. Clin J Pain 2002; 18: $270-3$

92. Russell IJ, Vaeroy H, Javors M, Nyberg F. Cerebrospinal fluid biogenic amine metabolites in fibromyalgia/fibrositis syndrome and rheumatoid arthritis. Arthritis Rheum 1992; 5: 550-6.

93. Giovengo S, Russell I, Larson A. Increased concen- tration of nerve growth factor in cerebrospinal fluid of patients with fibromyalgia. J Rheumatol 1999; 26: 1564-9.

94. Russell IJ. The promise of substance P inhibitors in fibromyalgia. Rheum Dis Clin N Am 2002; 28: 32942.

95. Wood PB. Stress and dopamine: implications for the pathophysiology of chronic widespread pain. Med Hypotheses 2004; 62: 420-4.

96. Malt EA, Olafsson S, Aakvaag A, Lund A, Ursin H. Altered dopamine D2 receptor function in fibromyalgia patients: a neuroendocrine study with buspirone in women with fibromyalgia compared to female population based controls. J Affect Disord 2003; 75: 77-82.

97. Buskila D, Press J. Neuroendocrine mechanisms in fibromyalgia-chronic fatigue. Best Pract Res Clin Rheumatol 2001; 15: 747-75.

98. Martinez-Lavin M. Biology and therapy of fibromyalgia. Stress, the stress response system and fibromyalgia, Arthritis Res Ther 2007; 9: 216.

99. Vaeroy H, Qiao Z-G, Morkrid L, Forre O. Altered sympathetic nervous system response in patients with fibromyalgia (Fibrositis syndrome). J Rheumatol 1989; 16: 1460-5.

100. Cohen H, Neumann L, Kotler M, Buskila D. Autonomic nervous system derangement in fibromyalgia syndrome and related disorders. IMAJ 2001; 3: 755-60.

101. Kooh M, Martinez-Lvin M, Meza S, Martin-del-Campo A, Hermosillo AG, Pineda C, Nava A, Amigo MC, Drucker-Colin R. Concurrent heart rate variability and polysomnography analyses in fibromyalgia patients. Clin Exp Rheumatol 2003; 21: 529-30.

102. Furlan R, Colombo S, Perego F, Atzeni F, Diana A, Barbic F, Porta A, et al. Abnormalities of cardiovascular neural control and reduced orthostatic tolerance in patients with primary fibromyalgia. J Rheumatol 2005; 32: 1787-93.

103. Anderberg UM, Liu Z, Berglund L, Nyberg F. Elevated plasma levels of neuropeptide $\mathrm{Y}$ in female fibromyalgia syndrome patients. Eur J Pain 1999; 3: 19-30.

104. Wallace D, Linker-Israeli M, Hallegua D, Silverman S, Silver D, Weisman M. Cytokines play an aetiopathogenetic role in fibromyalgia: a hypothesis and pilot study. Rheumatology 2001; 40: 743-9.

105. Abeles AM, Pillinger MH, Solitar BM, Abeles M. Narrative Review: The Pathophysiology of Fibromyalgia. Ann Int Med 2007; 146: 726-34.

106. Van Houdenhovea B, Egle U.T. - Fibromyalgia: a stress disorder? - Psychother Psychosom 2004; 73: 267-75. 